\title{
Current Hot Topics as Inspirational Resources for Motivating Students in Speaking Activity
}

\author{
Daban Saber Qader \\ University - Iraq \\ Email: daban.saber@epu.edu.iq \\ Hiam Saber Abbo \\ English Department, Faculty of Education, Soran University - Iraq \\ Email: hsa577@ene.soran.edu.iq
}

Department of Information Technology, Choman Technical Institute, Erbil Polytechnic

\begin{abstract}
The present study aims at showing hot topics as inspirational resources for speaking activities. It highlights the role of motivation in language learning and the activities used in speaking skill in the English language classrooms. The study aims at realizing the most motivating topics that learners prefer for speaking activities, and also it shows the role of motivation in having such topics and the difficulties facing learners while having topics for discussion. It also demonstrates the extent to which topic discussion helps students improve their speaking skill. For the methodology, a mixedmethod has been used and it is done in two stages. First, some topics in speaking books are selected and utilized in designing a questionnaire. The questionnaire consisted of three sections. The first and the third section consisted of a number of close-ended questions, while the second section composed of 6 open-ended questions. Based on the findings of the study, the topic 'Travel' was found motivating for Kurdish EFL learners. The results also revealed that some difficulties such as lack of motivation, lack of speaking skills, unfamiliarity with a topic, difficulty of a topic, a topic which is not culturally appropriate, and having no prior knowledge of the topic are difficulties facing second-language learners while having a topic for class discussion and speaking activity.
\end{abstract}

Keywords: Hot Topics, Inspirational Resources, Motivating Students, Speaking Activity. 


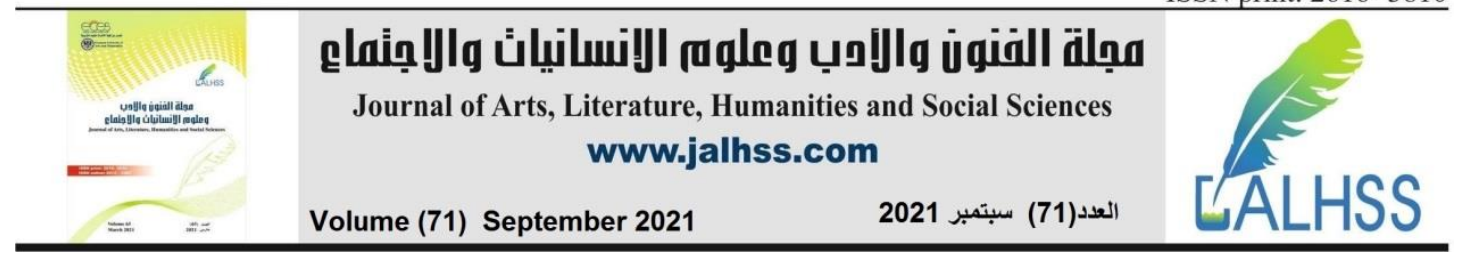

\section{Theoretical background}

The term topic does not lend itself to an easy definition perhaps because it is considered as a complicated term in communication; it refers to something, which means the topic, being discussed as cited in (Abdilah \& Shiri, 2020). A more detailed discussion of the role of a topic in speaking performance is presented by (Ur, 2009)who states appropriate topics provide the opportunities for learners to utilize their ideas, however, ability-grouping topics best facilitate most of them (p.123). Students must be given topics that they already have familiarity with them. As (Maxom, 2009)states while preparing lessons for class discussion, the chosen subjects should be fascinating. Furthermore, a common-made mistake which almost every educator makes is that they choose a topic for discussion which students have never talked about it in their native language. Also, it is a good idea to take into consideration learners' age and background while selecting a topic for class discussion. Topics should be age-appropriate. Moreover, they should contain entertaining topics music, movies, art or topics related to family, and finding a job are appropriate.

\section{Literature Review:}

Many researchers have investigated either topic-based activities or topics that are effective for speaking classes. (Bright \& Weeden, 2020)Have investigated educator's perspective on whether controversial topics, terrorism as an example, have an impact on students' skill improvement. The findings claim that controversial topics could be useful in improving learners' skills and information, so teachers' perception towards discussing such topics is positive. A study by (Young, 2019) Students perceptions of textbook topics in a discussion course has investigated second-language learners' perception of 24 topics in a course in terms of interest and familiarity. Based on the findings, among those topics, topics related to university and undergraduates' life are found interesting and familiar. In another study (Young, 2016)has discussed textbook revision in English discussion class, and has concluded that in the spring semester, the most rated topics is making friends at university and the reason of attending to university. Meanwhile, in the autumn semester, study abroad and English in Japan topics are rated by students. These topics are categorized as school/education or academic life.

Furthermore, a study by (McKay, 2013)has investigated teaching English language as an international language in the Chilean context. She has stated that when teachers teach English language, they should take into consideration the local culture topics. In another study (Wolf, 2013)has examined Japanese EFL learners perceptions of selecting a topic by themselves and the topics of textbooks. The findings have shown that having selected topics by themselves, learners feel confident while discussing the topics. More importantly, he has suggested that students should be given the opportunity to select topics for class discussions since it develops students' willingness to communicate.

On the other hand, the authenticity of textbook topics in comparison to conversation 


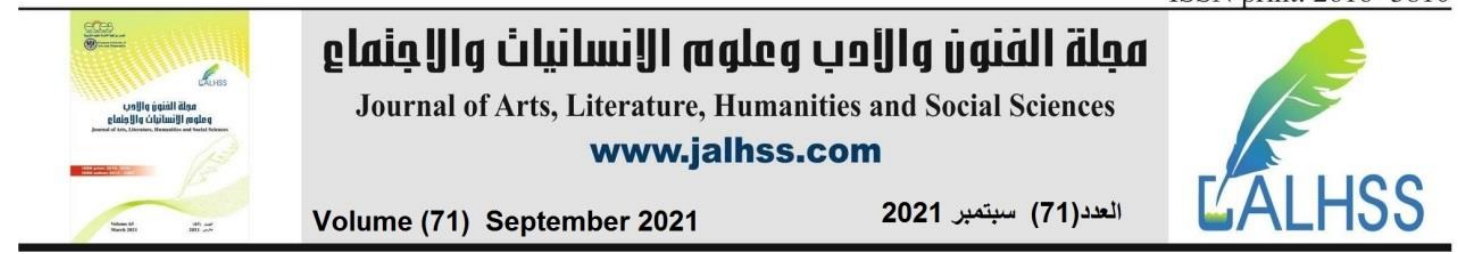

topics from international students' point of view has been argued by (Siegel, 2014)In the light of the study findings, local topics have been selected in conversation, while, universal topics have been chosen in textbooks. In addition, the local topics are Japanese culture and food, but, universal topics are 'the self' and everyday topics. Additionally, she suggests inclusion of topics that are relevant to school life to textbooks. An investigation by (Kitzman, 2016)into working to meet students' needs with optimal topics, Kitzman argues in order to inspire students, improve autonomy, and have meaningful learning ways in which topics are selected ought to be improved. Attempts to investigate willingness to communicate from different contexts have aroused interest among scholars, linguists, and applied linguists at large, and many of them have argued that topic is considered as a factor that affects students' willingness to communicate.

Most studies by (Aubrey, 2020), (Basoz \& Ertan, 2019) (Fadilah, 2018)have drawn the conclusion that topic, according to some of them topic relevancy, topic interest and topic familiarity, could be deemed as a factor having a great impact on foreign language learners willingness to communicate in class discussions. Some other researchers have examined the effects of topic familiarity on students' speaking performance. An investigation by (Shabani, 2013)into the impact of background knowledge on oral ability of Iranian learners has concluded that background knowledge, which can be referred to topic familiarity, greatly has an impact on students' speaking performance because it has learners to perform in a better way. Similarly, a study carried out by (Kazemi \& Zarei, 2015) has argued the influence of topic familiarity on oral presentation, and have found that the familiarity of a topic could be important as it helps students to speak more. Being familiar with topics, it enables learners to speak more.

\section{Speaking skills and activities in second language}

It goes without saying that speaking is the most important skill in English language learning because it is a key factor in having a successful conversation in another language which is, of course, the primary aim of every foreign-language learner. According to (Nunan, 2003) speaking skill is a productive-ability which comprises of verbal language in order to express sense (48). On the other hand, according to (Brown, 2004) speaking ability, which refers to speaking skill, could be noticed in a direct manner since it is a productive ability. Speakers of second-language learning are expected to have some basic elements in order to be able to speak the language properly. As (Harmer, 2007) states that in order for foreign language learners to possess the ability to speak the language, it is necessary to take some essential points into consideration such as correct phoneme pronunciation, appropriate use of stress and intonation, use of linking and connected speech, and good speaking ability in various contexts(343). Besides these abilities, they are supposed to gain common knowledge of language. (Thornbury, 2005) Mentions two kinds of knowledge directly related to language which is extra linguistic knowledge that is separable from language, and linguistic knowledge which is knowledge of characteristics of language. Extra linguistic types put speaking ability into effect include, topic and 


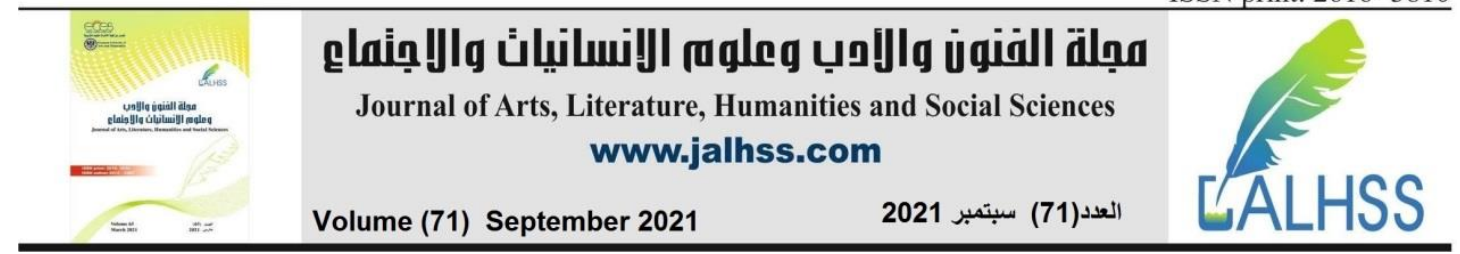

cultural knowledge, context knowledge. But, linguistic knowledge could include various levels such as, genre knowledge, pragmatic knowledge, discourse knowledge, grammar, vocabulary, and phonology.

In language teaching, the use of activities as a source of practicing the language skills is predominating in the classrooms. (Harmer, 2007) Points out current-used speaking activities are mainly found in communicative-based activities as following:

- Acting from a script: the provision of activities, such as scripts and acting out dialogues, can be acted out by learners, and good classroom environment should be provided as well.

- Communication games: communicative games come in different sorts, for example, information-gap games, television and radio games, and their objectives are to get students speaking.

- Discussions: they can be arranged in terms of a formal event and an informal interaction. Discussions such as buzz group, instant comment, formal debate, and unplanned discussions.

- Prepared talks: providing students with the opportunities to choose a topic and present it in the classroom.

- Questionnaires: the usefulness of the activity is that communication occurs between the students, and they create questionnaires about topics that are suitable.

- Stimulation and role-play: learners are given role-play in different contexts and situations so that they can act out as if they are in real life situations.

What inspires students to engage in activities and class discussion should be taken into account. According to (Harmer, 2001) there are three simple reasons why learners should be encouraged to involve in-class activities:

- Rehearsal: having given learners discussion, helps them to practice language outside classroom, when students participate in role-plays, they have the chance to practice language in class, and it gives them the idea of how communication takes place in language.

- Feedback: Not only speaking activities help students in practicing the language, they would also provide feedback for learners and educators. Educators can assess the class atmosphere, and find out what problems they are facing. Learners can get the easiest type of speaking and find out what should be worked on for improvement. Speaking tasks provide learners with self-confidence with the help of teachers.

- Engagement: learners will be satisfied with activities whenever they participate; the activity is given properly by the teacher and provides learners with feedback.

A large amount of studies has been conducted on speaking skills, and some other studies have investigated the role of activities and tasks on the development of foreign-language learners speaking performance. A study by (Tornqvist, 2008) has investigated students and educators' perspectives on spoken communication in English language as a second language. Most teachers and students share their 


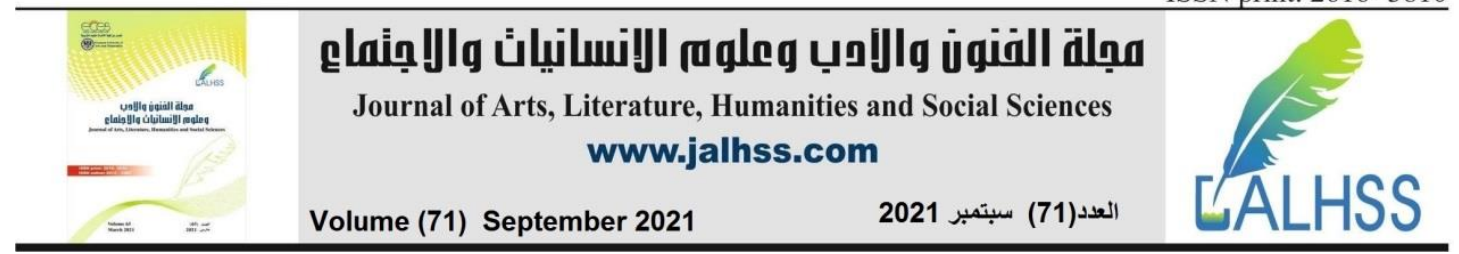

opinion that speaking skill is the most significant skill in second language learning as it helps to practice the target language. In addition, factors that impact students' active participation in communication in classroom are self-motivation, class atmosphere, homework, and teachers' inspiration. On the other hand, (Makalah, 2015) has carried out research into teaching speaking skill, and has drawn the conclusion that speaking skill, because it is considered as a significant skill, must be the most-learnt skill among all the other skills as it is a means of communication. (Becker \& Roos, 2016) have conducted research on an approach to creative speaking activities in the young students' classroom; they have concluded that young learners do not find speaking activities complicated; overall, they deem the tasks and activities likely develop their communicative competence. Some other scholars have done research on the effectiveness of specific activities on the foreign language learners' speaking performance. An investigation by (Aliakbar \& Jamalvandi, 2010) has discussed the influence of role-play activity on learners speaking ability. What they have concluded is that role-play as a speaking activity came into fruition after a two-month adaptation, and it could improve students' speaking performance.

Furthermore, (Prayoga, 2018) has conducted research to determine whether topicbased discussions in groups are useful in the improvement of learners speaking ability. Based on the study results, the researcher has noted the improvement of learners' speaking ability after being taught through topic-based activities and discussion in groups. A detailed investigation of designing communicative tasks for university learners has been done by (Cheng-Jun, 2006) stated communicative activities are effective in fostering learners' oral performance and competence as they encourage them to use the language. Similar to discussed study, research conducted by (Armadi, et al,. 2017) has discussed the use of communicative games on enhancing learners' speaking skill, and has concluded that the use of communicative games improve students' speaking ability; it also improves learners' motivation and selfconfidence during learning. Another study on communicative activities has been conducted by (Cabrera et al., 2016) has concluded that learners and educators beliefs towards communicative-based activities are positive, however, activities such as games, pair work, and role-play are found motivating and the ability of students' oral performance are clearly noticed. Moreover, research into the impact of debatable topics on improving learners' speaking ability by (Al-Tamimi, 2017) has proven that the use of debatable topics has a great effect on the improvement of learners' speaking skill. An investigation by (Fajariyah, 2009) into the use of games to improve students' speaking performance has concluded that learners' oral ability could be improved by using games. In addition, an action research by (Animilom, et al.,2014) has examined the use of oral presentations to boost students' confidence in speaking activities. The findings of the study have revealed that oral presentations could develop learners' confidence and motivation in speaking activities inside the classroom.

\section{The role of motivation in language teaching and learning}

Motivation has been a crucial aspect in most of the study area; it has been widely defined by many authors. 'Motivation is an internal state that arouses, directs and 
maintains behavior' as cited in (Bilal, et al., 2014) on one hand, motivation has an impact on second-language learners' rate of success and failure. In agreement to what mentioned, (Macklem, 2015, p. 38) claims 'Students' beliefs about whether or not they can be successful in school, or self-efficacy, is considered a motivational construct within models of self-regulated learning'. In the light of discussed definition, according to (Akoue, et al., 2015) motivation can be categorized into three types Intrinsic, extrinsic, and integrative motivation. Intrinsic motivation is an internal-cause, and students do actions because of their reasons. But, extrinsic motivation is an external-cause; students do actions in order to satisfy people. Integrative motivation is also extrinsic cause and actions are done for the sake of the adaptation to a group. (Kyriacou, 2004, p. 62) states that the development of learners' motivation is highly based on the provision of chances for them to gain control over learning, more importantly, educators must be able to examine students' low motivation causes, and they should find out the problem and give enough attention to it sufficiently. The role of motivation in language teaching and learning has been investigated by many scholars. A more considerable investigation of the role of motivation as a factor in language learning has been done by (Al-Ghamdi, 2014) and has concluded that extrinsic, intrinsic, and integrative motivation have a great impact on second-language learning, however, students must themselves be cautious about how motivation affects and influences them in learning the second language. (Alizadeh, 2016) Has investigated the impact of motivation on the English language learning; he has concluded that learners' motivation varies from one context of language-learning to another, and teachers have a huge influence in inspiring secondlanguage learners and motivation could be a significant part in language learning.

\subsection{Methodology}

\subsubsection{Method}

In the present study, Questionnaire is used. Also, the mixed-method approach, which is qualitative and quantitative method, is used for the purpose of the data collection.

\subsubsection{Participants}

The population of the study is students from Soran University-English Department in both Faculty of Education and Faculty of Arts. The number of students is 40 students from both faculties.

\subsubsection{Research instrument}

The study is completed in two stages. First, a considerable number of available and useable English course-books are chosen, and discussion topics from speaking section are chosen in order to design a questionnaire (appendix A). Second, a three-section questionnaire is designed, the first section consists of 12 closed-ended questions, the second section consists of 6 open-ended questions, and the last section consists of 6 closed-ended questions (appendix B).

\subsubsection{Data collection procedure}

The data are collected through a questionnaire that has three sections. It is distributed 


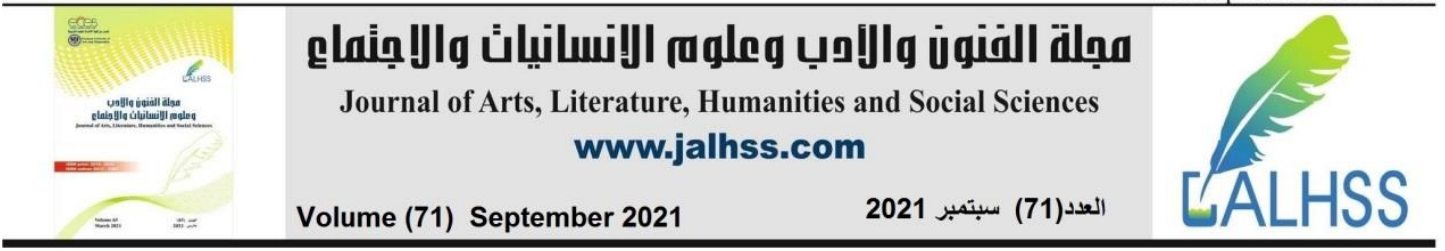

on students through their social media groups such as Viber and Telegram. Google drive services are used for the purpose of data analyses. The first section, which consists of 12 closed-ended questions, is analyzed through using its charts, the second section consists of 6 open-ended attitude questions and analyzed through learners' view points and responses written by students, and the third section also consists of 6 closed-ended questions analyzed through using its charts and tables.

\subsection{Results}

\section{Students' responses to the first section (12 closed-ended questions)}

Chart 1: students sorted by the faculty they are in.

Which faculty of Soran university are you in?

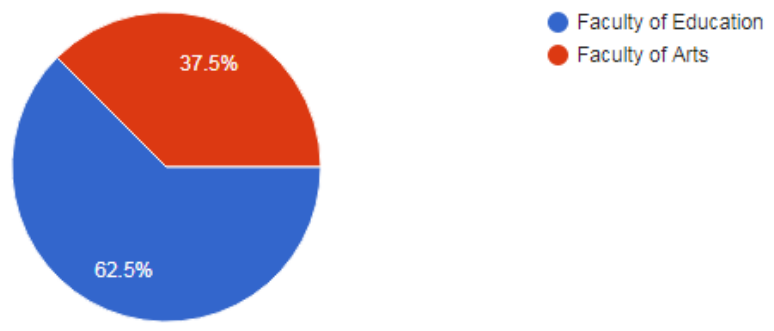

Chart 1 shows that the majority of participants is from faculty of education which is $25(62.5 \%)$, while, $15(37.5 \%)$ is from faculty of arts.

Chart 2: learners' age.

How old are you?

40 responses

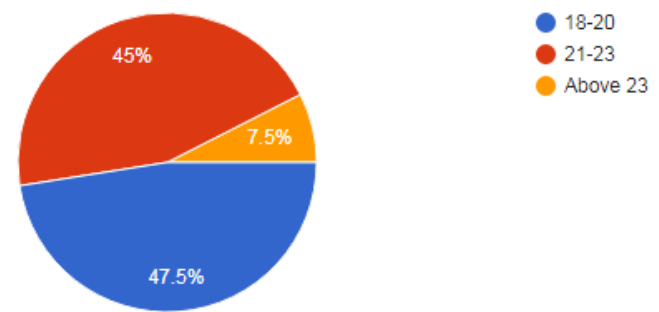

Based on chart 2, most of the learners are aged from eighteen to twenty which is 19 $(47.5 \%)$, while, the others are aged from twenty-one to twenty-three which is 18 (45\%). $3(7.5 \%)$ aged above twenty-three.

Chart 3: students' gender. 


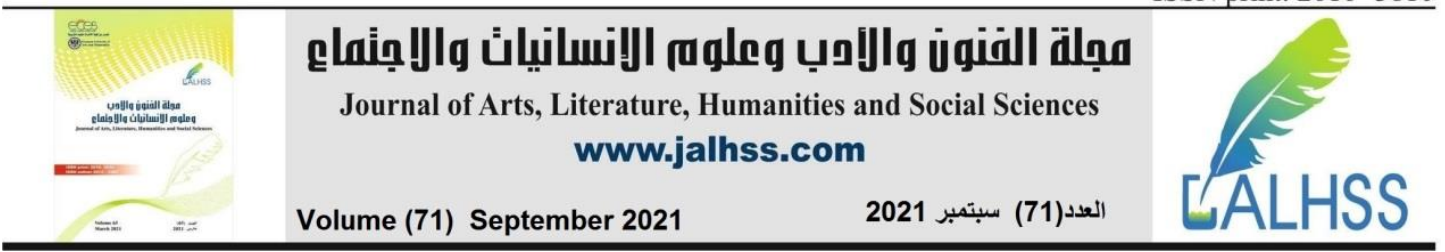

What is your gender?

40 responses

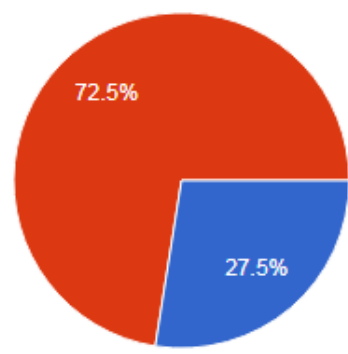

Chart 3 shows the majority of participants, who contribute to questionnaire, is female which is $29(72.5 \%)$, while, $11(27.5 \%)$ is male.

Chart 4: learners' point of view on 'Education system' topic

1. Education system

40 responses

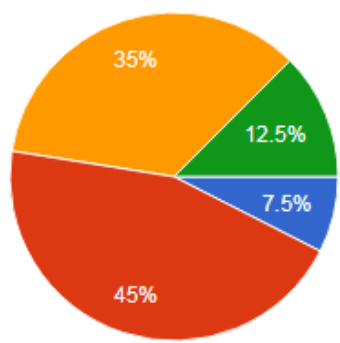

As illustrated in chart $4,45 \%$ of learners find Education system topic little motivating, $35 \%$ find it motivating, while, $12.5 \%$ rate the topic very motivating, and $7.5 \%$ find it not motivating.

Chart 5: students' point of view on 'Free time and weekend activities' topic

2. Free time and weekend activities

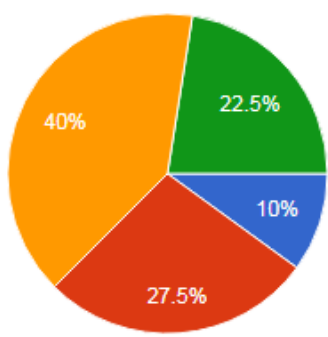

Chart 5 shows Free time and weekend activities topic is motivating by $40 \%$ of learners, $27.5 \%$ of them find the topic little motivating, while, $22.5 \%$ find it very motivating, and the topic is not motivating by only $10 \%$.

Chart 6: learners' Point of view on 'Business' topic 


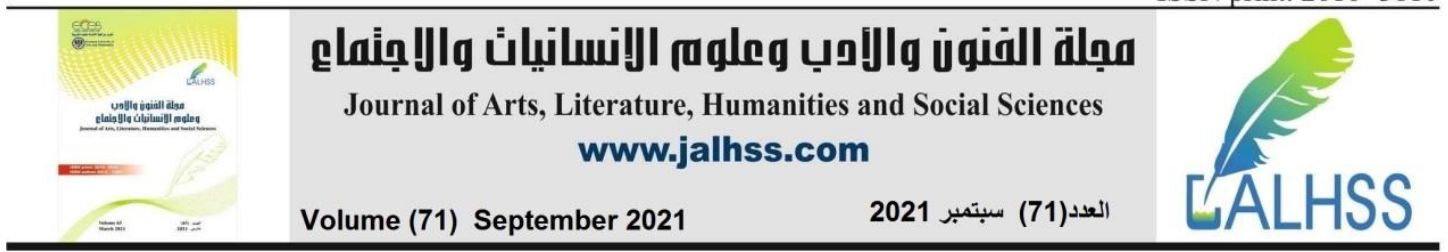

3. Business

40 responses

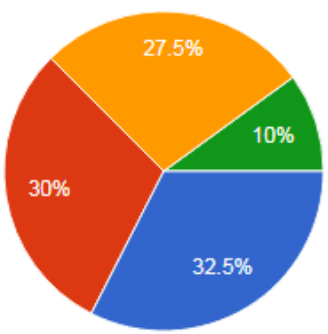

Little motivating

Motivating

Very motivating

Based on chart 6, the topic business is not motivating by $32.5 \%, 30 \%$ of students find the topic little motivating, and it is motivating by $27.5 \%$, while, $10 \%$ of learners find the topic very motivating.

Chart 7: learners' point of view on 'Musical experience' topic 4. Musical experience

40 responses

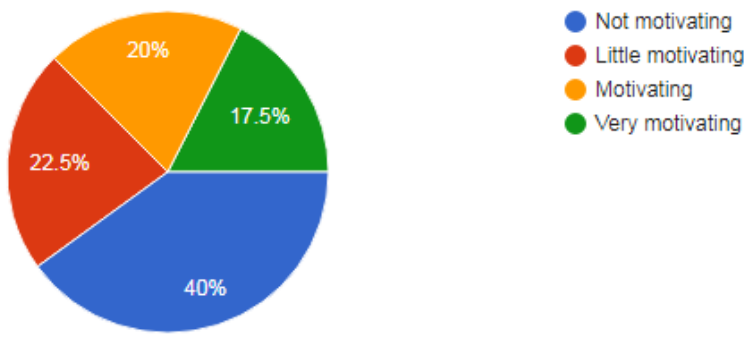

As chart 7 shows, $40 \%$ of students does not find musical experience motivating, it is little motivating by $22.5 \%$, and $20 \%$ of students find the topic motivating. The topic is very motivating by $17.5 \%$.

Chart 8: students' point of view on 'Social networking' topic

5. Social networking

40 responses

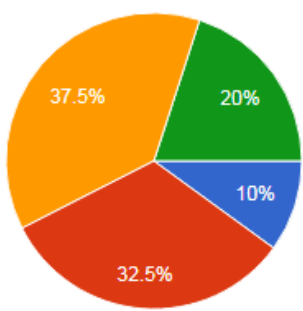

Not motivating

Little motivating

Motivating

Very motivating

Chart 8 displays the topic social networking is motivating by $37.5 \%, 32.5 \%$ of students find the topic little motivating, and the topic is very motivating by $20 \%$, while, the topic is not motivating by $10 \%$. 


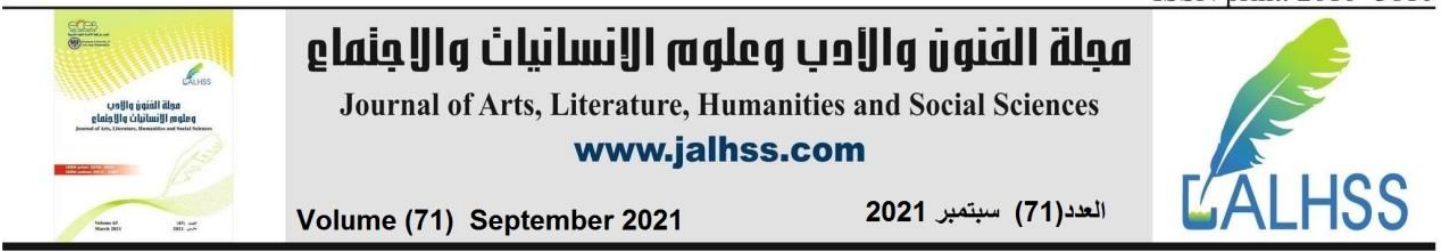

Chart 9: learners' point of view on 'Socializing' topic 6. Socializing

40 responses

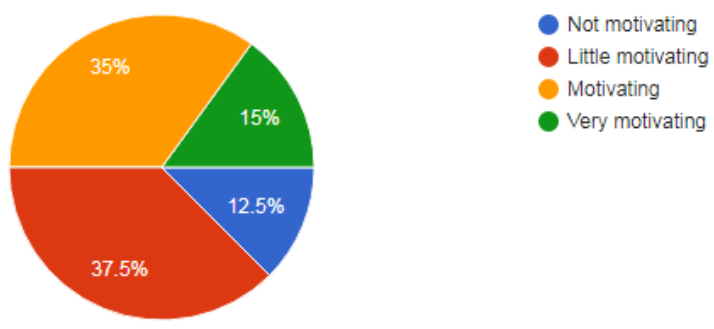

As chart 9 shows $37.5 \%$ of students find the topic socializing little motivating, while, it is motivating by $35 \% .15 \%$ of learners find the topic very motivating, and it is not motivating by $12.5 \%$.

Chart 10: learners' point of view on 'Travel' topic

7. Travel

40 responses
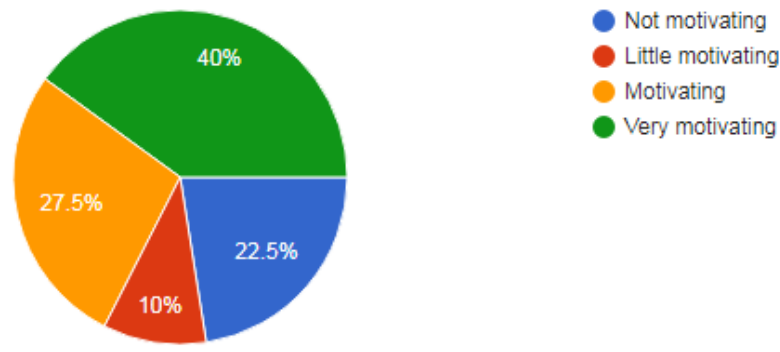

Chart 10 displays the topic travel is very motivating by $40 \%$, and $27.5 \%$ of learners find the topic motivating, however, the topic is not motivating by $22.5 \%$. It is little motivating only by $10 \%$.

Chart 11: learners' point of view on 'Shopping' topic

8. Shopping

40 responses

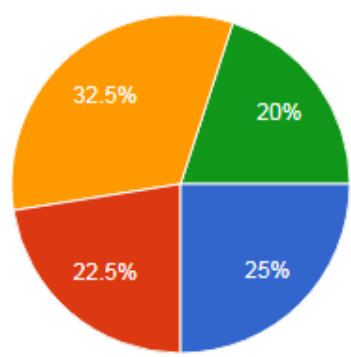




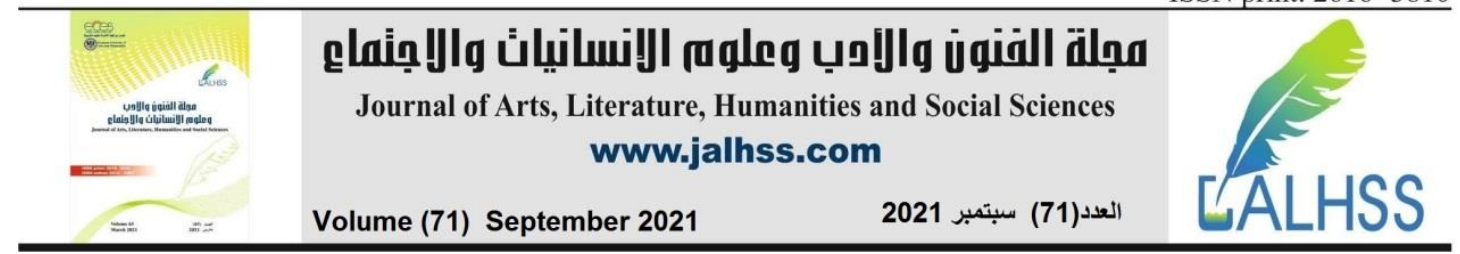

Based on chart 11 , the topic shopping is motivating by $32.5 \%$, and $25 \%$ of learners do not find the topic motivating. It is little motivating to $22.5 \%$ of learners, and only $20 \%$ find it very motivating.

Chart 12: learners' point of view on 'Holidays and festivals' topic 9. Holidays and festivals

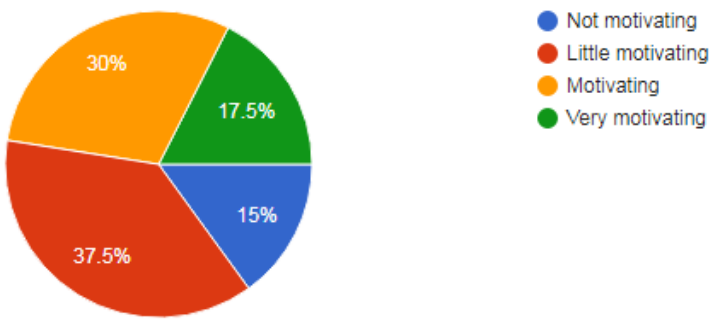

As chart 12 shows $37.5 \%$ of learners find the topic holidays and festivals little motivating, and it is motivating to $30 \%$. $17.5 \%$ of students view the topic very motivating, but $15 \%$ of them do not find it motivating.

\section{Students' responses to section two which is open-ended questions:}

Q1/ Please write down three other topics that motivate you in speaking activity.

The most written topics by students are watching movies, reading books, and talking to native speakers. Art, color, health, and family are some other topics written by students. Money, religion, social interaction, time, and learning languages are some other topics written by students.

Q2/Having chosen the motivating topic, what activities such as acting from a script, communication games, discussions, prepared talks, questionnaire, stimulation and role plays will you prefer to be followed? And why?

The majority of leaners preferred communication games because they are enjoyable and help students to learn better, and some others preferred discussion because it helps learners to communicate with others and learn from them. Conversation is chosen as students think they will be more involved with others and they talk more and some learners preferred questionnaire since it motivates students, and it is all about their opinions. Moreover, learners select speaking with friends because it does not make learners feel shy and acting from a script because it motivates learners to speak more. Some others think role plays are a good experience for students, and it meets their needs. Prepared talks are chosen since they are helpful for learning better.

Q3/ As a second-language learner, do you prefer international culture topics or local culture topics? Why?

Most learners prefer international culture topics because they are helpful in learning more information about the target language, and they help learners to make new friends and het to know different societies. Some others think local culture topics are vitally crucial to be protected, and they are proud of their culture.

Q4/ To what extent do you think topic discussion improves your speaking performance in class discussion? 


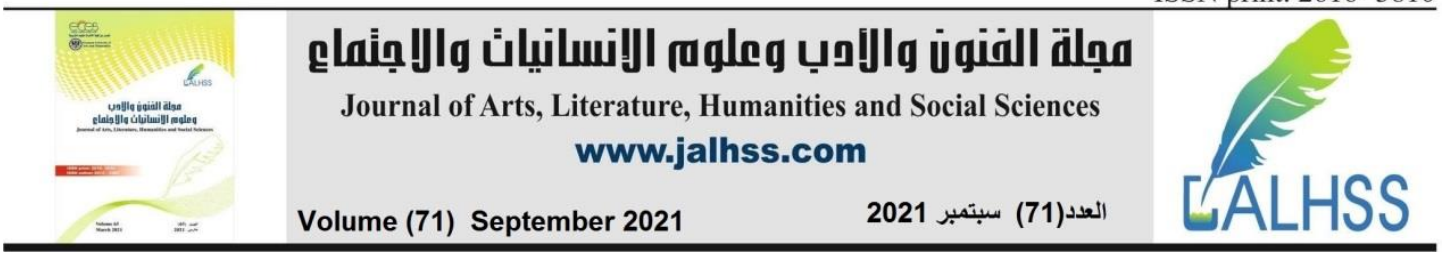

Most learners agree that topic discussion improves speaking performance to a high extent since learners will practice the target language in discussions, and it improves speaking skills.

Q5/ Do you think topic demotivates your participation in discussions? How?

Learners strongly agree that topic causes them to participate less in discussions. A topic which students dislike makes learners not participate in class activities, and a topic which students have no information about it demotivates them.

Q6/How do you think motivation enhances your participation in discussions?

Motivation improves learners' participation in class activities because it encourages students to speak more freely and without fear and hesitation. Motivation is one of the most important aspects in language learning.

\section{Learner's responses to third section which was close-ended questions:}

Chart 1: students' point of view on the difficulty 'Unfamiliarity with the topic'

1.Unfamiliarity with the topic

$0 / 40$ correct responses

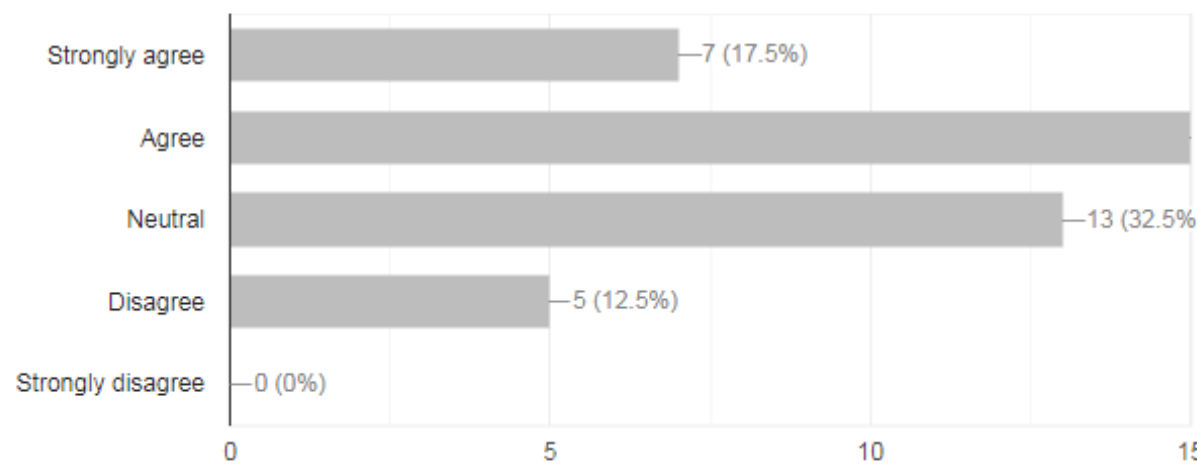

As illustrated in table $1,37.5 \%$ of students agree that they have found unfamiliarity with the topic a difficulty while having topics for speaking activity, and $17.5 \%$ strongly agree. $32.5 \%$ stay neutral, while, $12.5 \%$ disagree.

Chart 2: learners' point of view on the difficulty 'Culturally inappropriate' 


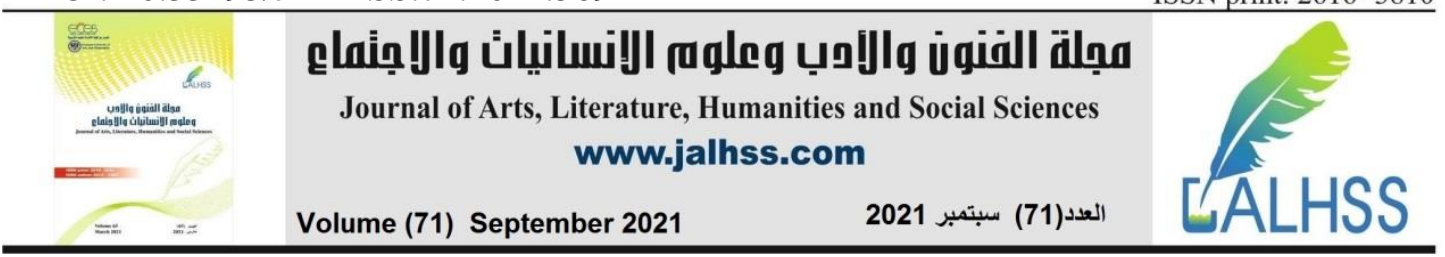

2.Culturally inappropriate

40 responses

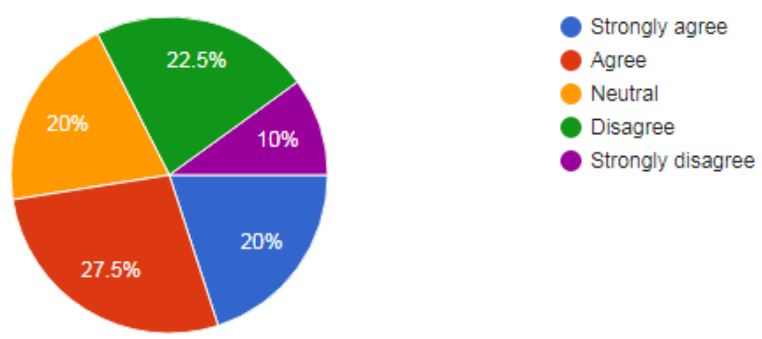

Chart 2 shows $27.5 \%$ of learners agree that a topic which is culturally inappropriate is a difficulty, and $22.5 \%$ of them disagree. However, $20 \%$ of learners strongly agree and $20 \%$ also stay neutral. Only $10 \%$ of students strongly disagree.

Chart 3: students' point of view on the difficulty ' No background knowledge of a topic'.

3.No background knowledge of the topic

40 responses

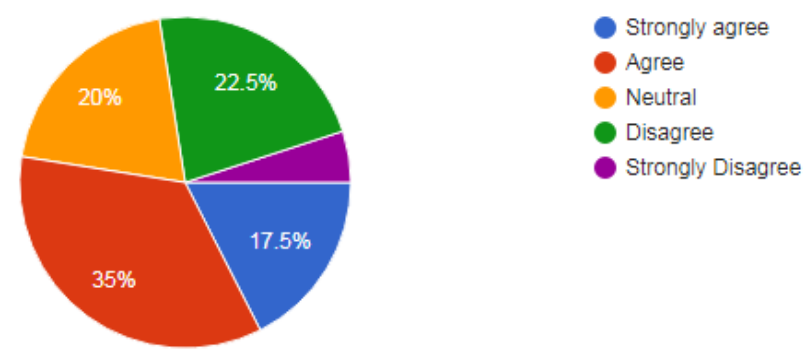

Chart 3 shows $35 \%$ of learners agree that having no knowledge of the topic is a difficulty, only $22.5 \%$ disagree. While, $20 \%$ stay neutral, and $17.5 \%$ of them strongly agree.

Chart 4: students' point of view on the difficulty 'Lack of speaking skills' 


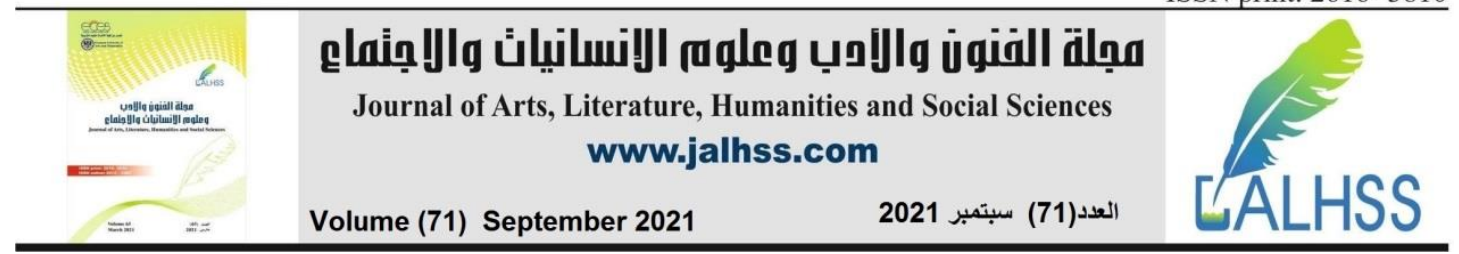

4.Lack of speaking skills

$0 / 40$ correct responses

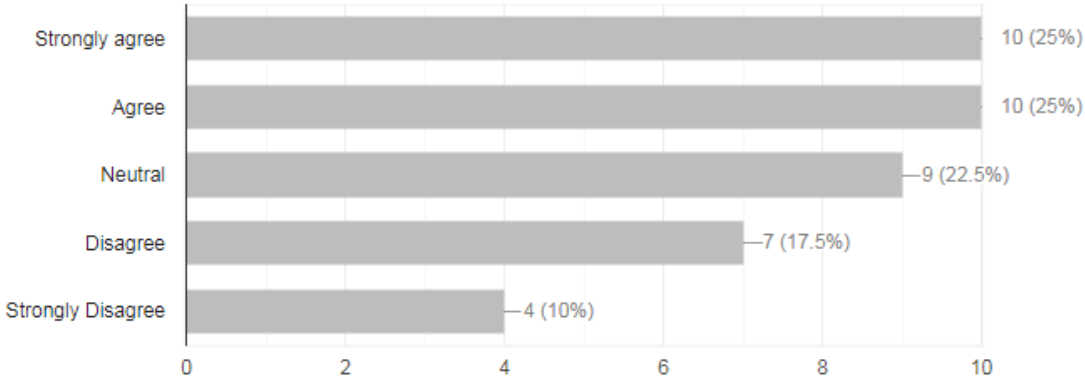

As illustrated in chart 4, 25\% of learners strongly agree that lack of speaking skill is a difficulty while having topics for discussion, and $25 \%$ of them also agree. $22.5 \%$ of students are neutral, and $17.5 \%$ disagree. However, only $10 \%$ strongly disagree.

Chart 5: learners' point of view on the difficulty 'Lack of motivation' 5.Lack of motivation

40 responses
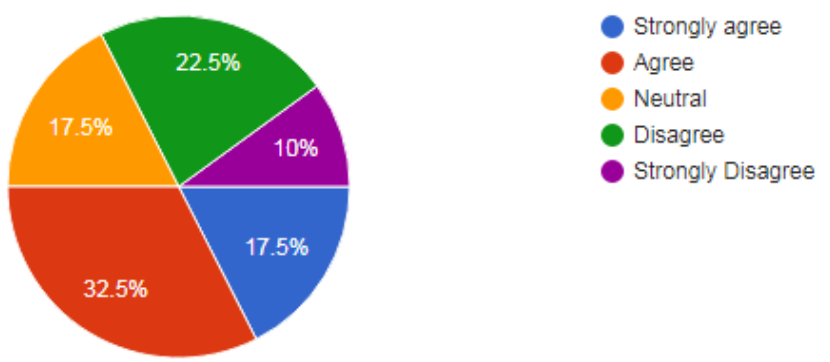

Chart 5 shows $32.5 \%$ agree that lack of motivation is a difficulty, and $22.5 \%$ of learners disagree. While, $17.5 \%$ stay neutral, but $17.5 \%$ strongly agree. Only $10 \%$ strongly disagree.

Chart 6: Students' point of view on the difficulty 'Topic difficulty' 6.Topic difficulty

40 responses

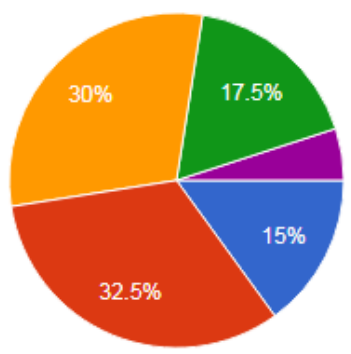




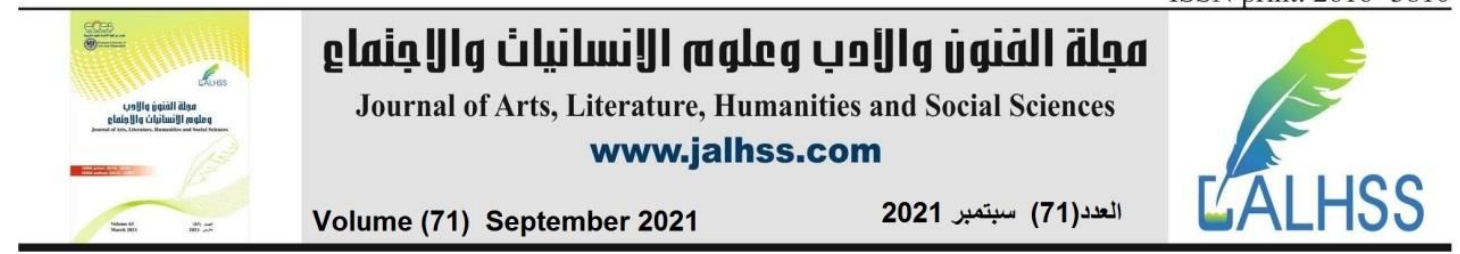

As chart 6 shows, $32.5 \%$ of learners agree that the difficulty topic difficulty face them while having topics for discussion, $30 \%$ stay neutral. $17.5 \%$ of students disagree, and only $15 \%$ strongly agree.

\subsection{Discussion}

Based on the well-analyzed results of the study, it could be seen that topics such as 'Education system' is little motivating among Kurdish ELF learners, and the topic 'Free times and weekend activities' is found motivating among them. Comparing to (Young, 2016)'s study, the topics related to school/education/ academic life are found intersting by most Japanese ELF students. The topic 'Education system' is little motivating for learners in speaking activity, meanwhile, most learners find the topic 'Free time and weekend activities' motivating. Moreover, the topic 'Business' is not motivating among learners, and the topic 'Musical experience' is not a motivating topic for learners. In addition, the topic 'Social networking' is motivating. Most learners view the topic 'Socializing' a little motivating, and the very motivating topic is 'Travel'. Moreover, the topic 'Shopping' is motivating as well, meanwhile, 'Holidays and Festivals' topic is little motivating for learners. From Kurdish secondlanguage learners viewpoints other most-common written topics are watching movies, reading books, and talking to native speakers. On the other hand, the majority of learners prefer communication games, discussion, and prepared talks. Kurdish EFL learners prefer international culture topics over local culture topics; it does not corresepand to (McKay, 2013)'s study. Similarly, most learners think that topic discussion improves their speaking ability, and it correspondes to (Prayoga, 2018)'s studies. Furthermore, students agree that a topic can discourage them from participating in speaking activities, and they also agree that motivation can improve their participation in class discussion. More importantly, the difficulties such as unfimilarity with a topic, culturally inapproriate topics, having no background of a topic, lack of motivation, lack of speaking skills, and difficulty of a topic are found difficulties facing learners while having topics for speaking activity which they corresponde to these studies (Shabani, 2013), (Kazemi \& Zarei, 2015), (Aubrey, 2020), (Basoz \& Ertan, 2019), (Fadilah, 2018). The limitations of the study are some learners responsed to some open-ended questions mistakenly, some others do not response to the questions. Only few topics are selected to be invistegated and some topics might be inappropriate to be selected. another limitation is the selection of stages in both faculties. From faculty of Education first, second and forth stage students are chosen, whereas, from faculty of Arts only first stage students are chosen because only these stages from both faculties are taking speaking skills courses.

\section{Conclusion:}

The current study aims at investigating hot topics as inspirational resources in speaking activity, additionally, the role of motivation and topic discussion in speaking skill and activity are studied. based on the findings, the study draws the conclusion that among 9 topics investigated in this study, the topic 'Travel' is very motivating and the topic 'Social networking' is found motivating in speaking activity for Kurdish 
EFL learners. In addition, the topics 'Business' and 'Musical experience' are not motivating. Also, among the written topics by learners, the topics 'Watching movies' and 'Reading books' are the preferred topics by learners. Teachers should pay heed to the selection of topics, and inappropriate topics ought to be avoided as they discourage learners from actively participating in speaking activities. Having the topics, speaking activities such as discussion and communication games should be followed in order for learners to have the benefit of topics and speaking activity. Chosen topics for speaking activity must be motivating as they can lead to demotivating learners in class activity. International culture topics should be taken into consideration. Furthermore, the findings of the study revealed that difficulties such as unfamiliarity with a topic, no background knowledge of a topic, culturally inappropriate, lack of speaking skill and motivation, and topic difficulty can have great impact on students' participation in speaking activity while having a topic for the activity. It is vital that instructor take heed of the mentioned difficulties since learners may face these difficulties and not be able to participate in speaking activities and class discussions. More importantly, mentioned difficulties and inappropriate topics greatly might affect students' willingness to communicate. The limitations of the study are only few topics are selected to be investigated and some topics might be inappropriate to be selected. Also, some learners answer some open-ended questions mistakenly; some others do not response to the questions. The study recommends more investigation into appropriate topics for learners particularly undergraduate students. It also recommends a study on topics from both genders' viewpoint. How different genders find topics for class discussions and their preferences.

\section{References}

1. Abdilah, H., \& Shiri, S. (2020). The lnfluence of topic management on the speaking ability of Iranian intermediate EFL learners. The international journal of Applied linguistics and English literature, 9(3), 62-69.

2. Akdeniz, N. o. (2017). Use of student-produced videos to develop oral skills in EFL classrooms.

3. Akoue, B., Allogo, J. O., Ndong, J.-C. N., \& Tennant, A. (2015). Starter teachers A methodology course for the classroom. London: British Council.

4. Al-Ghamdi, A. (2014). The role of motivation as a single factor in second language learning. ARECLS, 11, 1-14.

5. Aliakbar, M., \& Jamalvandi, B. (2010). The impact of 'role-play' on fostering EFL learners' speaking ability; A task-based approach. Pan-pacific Association of Applied linguistics, 14(1).

6. Alizadeh, M. (2016). The impact of motivation on English Language Teaching. International journal of research in English Education, 1(1).

7. Al-Tamimi, N. O. (2017). Improving speaking skill: implications for using debatable topics in English speaking class. Research journal of English language and literature, 5(4).

8. Animilom, S., Othman, A. B., \& Radzi , A. H. (2014). Using oral 


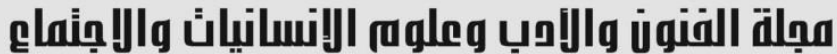 \\ Journal of Arts, Literature, Humanities and Social Sciences www.jalhss.com

presentations to enhance students' confidance in speaking task: An action research.

9. Armadi, A., Dewi, R. S., \& Kultsum, U. (2017). Using communicative games in improving students' speaking skills. English language teaching, 10(1).

10. Aubrey, S. (2020). Influences on Japanese students' willingness to communicate across three different sized EFL class.

11. Basoz, T., \& Ertan, I. H. (2019). A qualitative inquiry into the factors influencing EFL learners' in-class willingness to communicate in English. Novitas-ROYAL, 13(1), 1-18.

12. Becker, C., \& Roos, J. (2016). An Approach to creative speaking activities in the young learners' classroom. Education Inquiry, 7(1).

13. Bilal, H. A., Bibi, N., Nawaz, A., Rehman, A., \& Sheikh, A. (2014). The role of motivation in learning English language for Pakistani learners. International journal of Humanities and social science, 4(1).

14. Bohlke, D., \& Richards, J. C. (2012). Speak Now 1. New York: Oxford university press.

15. Bohlke, D., \& Richards, J. C. (2012). Speak now 3. New York: Oxford university press.

16. Bright , D., \& Weeden, K. (2020). Pre-service teacher attitudes towards discussing terrorism in English as an additional language(EAL) classrooms: citizenship, democratic practices, and the discussion of conroversial issues. The Austrailian Educational Researcher, 149-166.

17. Brown, H. D. (2004). Language Assessement Principles and Classroom Practices. New York: Pearson Education.

18. Cabrera, P., Castillo, L., Gonzalez, P., Ochoa, C., \& Quinonez, A. (2016). The effect of communicative activities on efl learners' motivation; a case study of students in Amazon region of Ecuador. Colomb Applied lingustics, 18(2), 39-48.

19. Cheng-Jun, W. (2006). Designing communicative tasks for colleage English courses.

20. Cunningham, G., \& Redston, C. (2013). Face2face (Second ed.). Cambridge: Cambridge university press.

21. Eales, F., \& Oakes, S. (2016). Speakout (Second ed.). Longman pearson.

22. Fadilah, E. (2018). Willingness to communicate from Indonosian learners' perspective. Journal of EIT Research, 3(2).

23. Fajariyah, D. N. (2009). Improving students' speaking proficiency using games.

24. Harmer, J. (2001). How to teach English. Harlow: Pearson Education.

25. Harmer, J. (2001). How to teach English. Harlow: Pearson Education.

26. Harmer, J. (2007). The practice of English Language Teaching. Harlow: Pearson Education.

27. Hull, J., Proctor, S., \& Richards, J. C. (2013). Interchange 1. New York: Cambridge university press.

28. Jodaei, H., \& Yegani, H. (2018). The effect of Task-based and Topic-based 


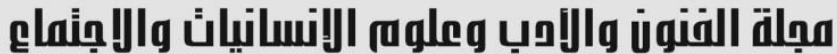 \\ Journal of Arts, Literature, Humanities and Social Sciences www.jalhss.com

speaking activities on speaking ability of Iranian EFL learners. International journal of English language and Translation Studies, 5(4), 85-93.

29. Kazemi, S. A., \& Zarei, L. (2015). The efficacy of topic familiarity on oral presentation: extensive speaking assessment task of Iranian EFL learners in TBLT. International journal of applied linguistics and language literature, 4(3).

30. Kitzman, A. (2016). Working to meet students' needs with optimal topics. OnCUE Journal, 9(3), 239-260.

31. Kyriacou, C. (2004). Effective teaching in schools theory and practie. Cheltenham: Nelson Thornes Ltd.

32. Lan, D. T., Houng, N. T., \& Van, D. T. (2020). The use of pop songs in enhancing English speaking skills of first year students at Thai Nguyen university of Economics and business administration - TNU. IOSR journal of Reseach and Method in Education, 10(2), 29-36.

33. Lieske, C., \& Vargo, M. (2012). Speak now 4. New York: Oxford university press.

34. Macklem, G. L. (2015). Bordem in classroom adressing student motivation, self-regulation, and engagement. Switzerland: Springer International Publishing.

35. Makalah. (2015). Teaching Speaking.

36. Maxom, M. (2009). Teaching English as a foreign language for Dummies. Chichester: John Wiley and Sons.

37. McKay, S. (2013). Teaching English as an international language: Chilean context. ELT Journal, 57(2).

38. Nunan, D. (2003). Practical English Language Teaching. Singapore: McGraw-Hill.

39. Phillips, A., Phillips , T., \& Regan, N. (2013). General English. UK: Garnet Publishing.

40. Prayoga, F. (2018). The impact of topic-based group discussion on EFL learners' speaking performance. IOSR Journal of Research and Method in Education, 8(2), 40-45.

41. Prayoga, F. (2018). The impact of Topic-based Group discussion on EFL learners speaking performance. IOSR journal of Reseach and Method in Education, 8(2), 40-45.

42. Shabani, M. B. (2013). The effect of background knowledge on speaking ability of Iranian EFL learners. International Samanm journal of marketing and management, 1(1).

43. Siegel, A. (2014). What should we talk about? The authenticity textbook topics. ELT Journal, 68(4), 363-375.

44. Thornbury, S. (2005). How to teach speaking. Harlow: Pearson Education.

45. Tornqvist, A. (2008). A study of attitudes of some English teachers and 9th grade pupils in Sweden towards oral communication in the English classroom. English C, 15 ECTS.

46. Ur, P. (2009). A course in language teaching: practice and theory. 


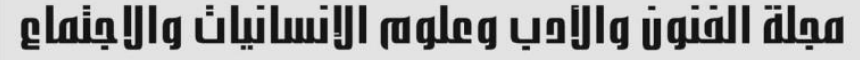 \\ Journal of Arts, Literature, Humanities and Social Sciences www.jalhss.com

Cambridge: Cambridge University Press.

47. Wolf, J. P. (2013). Exploring and contrasting EFL learners' perceptions of textbook- assigned and self-selected discussion topics. SAGE Journals, 17(1), 49-66.

48. Yegani, H., \& Jodaei, H. (2017). The effect of task-based and Topic-based avtivities on speaking ability of Iranian EFL learners. International journal of English Language and Translation studies, 5(4), 85-93.

49. Young, D. (2016). Textbook revision in the EDC context: Readability and interest. OCJSI.

50. Young, D. (2019). Students perceptions of textbook topics in a discussion course. OCJSI, 107-127. 